\title{
PHYSICOCHEMICAL PROPERTIES OF MODIFIED TRIFOLIATE YAM STARCHES
}

\author{
Abiodun O.A. ${ }^{1 *}$, Odedeji, J.O. ${ }^{2}$, Adepeju, A.B. ${ }^{3}$ and Oladapo A.S. ${ }^{2}$ \\ ${ }^{1}$ Department of Home Economics and Food Science, University of Ilorin, Kwara State, Nigeria. \\ ${ }^{2}$ Department of Food Science and Technology, Osun State Polytechnic, Iree, Nigeria. \\ ${ }^{3}$ Department of Food Science and Technology, Joseph Ayo Babalola University, Ikeji-Arakeji, Osun State, Nigeria. \\ *Corresponding author's email: funmiabiodun2003@yahoo.com Tel: +2348030701354
}

(Received: $15^{\text {th }}$ December, 2017; Accepted: $1^{\text {st }}$ March, 2018)

\section{ABSTRACT}

\begin{abstract}
Physicochemical properties of modified trifoliate yam starches were determined. Trifoliate yam starches were harvested and the starch was extracted. The extracted starch was modified using four methods (acid and alkali treatment, oxidation and acetylation). Colour and physicochemical properties of the modified starches were determined. Colour of pre-gelatinized trifoliate yam starch was significantly different $(p<0.05)$ from other starches. The colour was yellowish/reddish while other starches were lighter in colour. The structures of untreated, oxidized, pre-gelatinized and acetylated starches were polygonal in shape. Granule sizes of native and modified trifoliate yam starches ranged from 2.53 to $3.86 \mu \mathrm{m}$. Amylose content of trifoliate yam starches ranged from 10.01 to $16.17 \%$. Swelling power of pre-gelatinized starch increased from 2.15 at $60^{\circ} \mathrm{C}$ to 3.00 at $70{ }^{\circ} \mathrm{C}$ but the values decreased at 80 to $90^{\circ} \mathrm{C}$. Acid-treated starch exhibited higher paste clarity at refrigerated temperature than ambient temperature but at ambient temperature, oxidized starch had high paste clarity during storage. Acid and alkali-treated starches had higher water exudate at day 0 which later decreased with storage. Acetylated starch had higher peak viscosity $(3833.00 \mathrm{cP})$. Acid and alkali treatment reduced the viscosities and had low freezethaw stability.
\end{abstract}

Keywords: Colour, Modification, Physicochemical, Trifoliate yam starch

\section{INTRODUCTION}

Starch is one of the most important polysaccharides found in many food plants and consists of amylose and branched amylopectin molecules (Tako et al., 2014). According to Santana et al. (2014), starch is a macro-constituent of many foods and is widely consumed by humans as an inexpensive and stable carbohydrate source. It is useful in food production, cosmetics, paper, textile, as adhesive, thickening, stabilizing, stiffening and gelling agents (Tako et al., 2014). Thys et al. (2013) also reported starch as the most common thickening and gelling agent used by the food industry in the development of a large number of products such as soups, sauces, and ready-to-eat food among others.

Native starches have some limitations in their use in the food industry due to low shear resistance, thermal resistance, thermal decomposition and a high tendency towards retrogradation (Odeniyi and Ayorinde, 2012; Otegbayo et al. 2013). Therefore, starch can be structurally modified by various means to enhance its functions as an ingredient (Chung et al., 2008; Eliasson and
Gudmundsson, 1996). Native starches are modified in order to improve their functional properties and these can be done using physical (heat-moisture, steam-pressure, microwave irradiated), chemical (acid treatment, oxidation, cross-linking, acetylation, succinylation, phosphorylation, hydroxypropylation and carboxymethylation) and enzymatic technique (Abbas et al., 2010; Jyothi et al., 2013). Modification of other starches from corn, cassava, potato and some yam species had been reported (Jyothi et al., 2013; Adetunji et al., 2006; Zięba et al., 2010; Okunola and Akingbala, 2013). Modification of trifoliate yam starches for industrial application had not been extensively researched like other yam species. This may be due to the problems (hardening and presence of bitter principle) associated with this yam species thereby limiting the cultivation and market value of the crop. Starch granules of trifoliate yam are smaller than other yam species which signified higher digestibility of the starch (Akinoso and Abiodun, 2013). Therefore, this work determined the physicochemical properties of modified trifoliate yam starches. 


\section{MATERIALS AND METHODS}

Freshly harvested trifoliate yam tubers were obtained at a farm in Osun State Polytechnic, Iree, Nigeria. Method of Akinwande et al., (2007) was used for starch extraction. Acid-modified starch was produced according to Okunola and Akingbala (2013) using 6\% $\mathrm{HCl}$ solution and neutralized with $10 \%$ (w/v) $\mathrm{NaOH}$ solution. Alkali-modified starch was produced using the method of Gutiérrez et al., (2014) while acetylated and oxidized starches were produced using methods of Sathe and Salunkhe (1981) and Iheagwara (2012) respectively. Pre-gelatinized starch was done according to method of Oladebeye et al., (2011).

The colour attributes ( $\mathrm{L}$, $\mathrm{a}$, and $\mathrm{b}$ values) of the yam starch was measured using a Minolta portable chroma-metre. The colour coordinates system $L^{*}$ $a^{*}$ and $b^{*}$ values were recorded.

Morphological structure of starch was done using a light microscope (LM) and stained with drops of potassium iodide (KI) solution. The images were viewed at a magnification of x 400 (AmScope Binocular Digital Microscope version x86, 3.7.4183). The area, perimeter and diameter of the starch granules were measured and used to calculate the granule sizes and form factor. Amylose determination was done using the method of Juliano (1971). The stability and clarity of starch pastes were determined at $27^{\circ} \mathrm{C}$ and 4 ${ }^{\circ} \mathrm{C}$ following the method of Gutiérrez et al., (2014). The percentage (\%) transmittance at 650 $\mathrm{nm}$ was determined in a spectrophotometer (BKUV1600PC) using distilled water as a blank. Method of Lutfi and Hasnain (2013) was used for freeze-thaw stability at $5 \%$ starch solution.

Moisture and swelling power determination were carried out using the procedure of AOAC method
934.01 (AOAC, 2006) and Peroni et al., (2006) respectively. The pasting profile of the starch sample was studied using a Rapid Visco-Analyzer (RVA) (Newport Scientific Pty Ltd) with the aid of a thermocline for windows version 1.1 software.

\section{Statistical Analysis}

All procedures were carried out in triplicates. The mean and standard deviation of the data obtained was calculated. The data were evaluated for significant differences in their means using Analysis of Variance at $p \leq 0.05$. Differences between the means were separated using Tukey's test.

\section{RESULTS AND DISCUSSION}

\section{Effect of modification on colour of trifoliate yam starches}

Alkali-treated starch was significantly different $(p<0.05)$ from oxidized and pre-gelatinized starches in lightness value (Table I). The alkalitreated starch colour was lighter than other starches but the value obtained was not significantly different $(p<0.05)$ from native, acetylated and acid-treated starches. Modification significantly improved the color value (whiteness) of acid and alkali-treated, acetylated and oxidized starches. Pre-gelatinized starch had lower $\mathrm{L}^{*}$ value (59.66) but higher $\mathrm{a}^{*}$ and $\mathrm{b}^{*}$ values of 3.76 and 9.40 respectively, which were significantly different $(p<0.05)$ from other starches. Pregelatinized starch colour tends toward reddish and yellowish than other samples. Pre-gelatinized trifoliate yam starch could be used in products requiring coloured materials such as soup, jellies and so on due to imparted colour during modification. Colour is one of the important parameters that affect the product acceptability in the food industry. 
Table I: Effect of modification on the colour of trifoliate yam starch

\begin{tabular}{llll}
\hline Treatment & $\mathrm{L}^{*}$ & $\mathrm{a}^{*}$ & $\mathrm{~b}^{*}$ \\
\hline RY & $87.99 \pm 1.11 \mathrm{ab}$ & $1.29 \pm 0.06 \mathrm{~b}$ & $5.94 \pm 0.26 \mathrm{c}$ \\
AEY & $86.46 \pm 0.87 \mathrm{ab}$ & $0.88 \pm 0.14 \mathrm{~d}$ & $5.40 \pm 0.42 \mathrm{c}$ \\
ADY & $88.100 \pm 0.39 \mathrm{ab}$ & $1.12 \pm 0.07 \mathrm{bc}$ & $7.31 \pm 0.07 \mathrm{~b}$ \\
AKY & $89.39 \pm 0.41 \mathrm{a}$ & $0.96 \pm 0.08 \mathrm{~cd}$ & $7.63 \pm 0.12 \mathrm{~b}$ \\
OY & $86.09 \pm 1.66 \mathrm{~b}$ & $0.01 \pm 0.01 \mathrm{e}$ & $6.02 \pm 0.51 \mathrm{c}$ \\
PY & $59.66 \pm 1.79 \mathrm{c}$ & $3.76 \pm 0.9 \mathrm{a}$ & $9.40 \pm 0.23 \mathrm{a}$ \\
\hline
\end{tabular}

Values with the same superscript down the column were not significantly different $(\mathrm{p}<0.05)$

RY- Raw yam starch, AKY-Alkali-treated starch, ADY-Acid-treated starch, OXY-Oxidized starch, PYPre-gelatinized starch, AEY-Acetylated starch
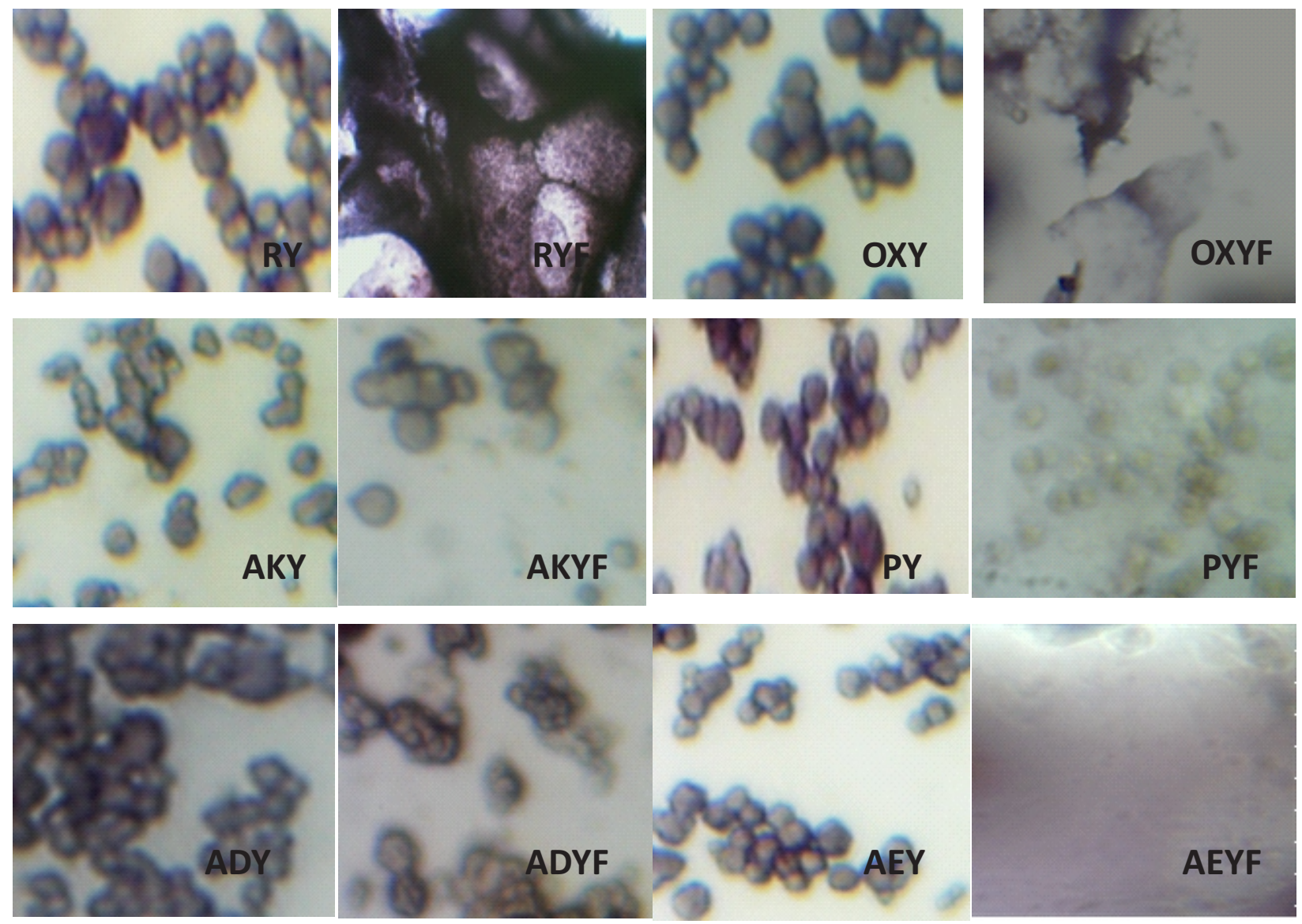

Figure I: Effect of modification and freeze-thaw on the morphological structure using light microscope (x $400 \mu \mathrm{m})$ of trifoliate yam starches

RY-Raw yam starch, RYF-Raw yam starch after freezing, AKY-Alkali-treated starch, AKYF-Alkalitreated starch after freezing, ADY-Acid-treated starch, ADYF-Acid-treated starch after freezing, OXYOxidized starch, OXYF-Oxidized starch after freezing, PY-Pre-gelatinized starch, PYF-Pre-gelatinized starch after freezing, AEY-Acetylated starch, AEYF-Acetylated starch after freezing 

Effect of Modification on Morphological
Structure of Trifoliate Yam Starches

The morphology of the starch granules is presented in figure I. The structures of untreated, oxidized, pre-gelatinized and acetylated starches were similar in shape. The shapes were polygonal but those of alkali and acid-treated starches did not have a definite shape and were attached. Acid and alkaline starches were not smooth like other untreated and other modified starches. After 10 freeze-thaw cycle, the untreated starch had a swollen starch structure with rough surfaces. Alkali and acid-treated starches had rough surface granules joined together. The oxidized starch structure had smooth surfaces but with fissures while acetylated starch had rough surfaces with perforations. Sukhija et al., (2016) observed surface fissures in case of oxidized and oxidized cross-linked starch and smooth surface of native, cross-linked and cross-linked oxidized starches. According to Wang and Copeland (2015), acid hydrolysis can significantly change the structural and functional properties of starch without disrupting its granular morphology and that amorphous regions are hydrolyzed to enhance the crystallinity and double helical content of acidhydrolyzed starch.

\section{Effect of Modification on the Granule Size, Amylose and Moisture Contents of Trifoliate Yam Starches}

Granule sizes of trifoliate yam starches ranged from 2.53 to $3.86 \mu \mathrm{m}$ (Table II). There were significant differences $(p>0.05)$ in the values obtained for pre-gelatinized starch (PY) and other starches. PY had the highest value in granule size $(3.86 \mu \mathrm{m})$ while the least value was in acetylated starch (AEY). There were no significant differences $(\mathrm{p}<0.05)$ in granule sizes of alkali and acid-treated starches. Starch granule size values were within the range reported by Akinoso and Abiodun (2013). Granule sizes of trifoliate yam starch are smaller and thereby are more digestible than some yam starches. Amylose content of trifoliate yam starches ranged from 10.01 to $16.17 \%$. Amylose contents of acetylated starch were significantly different $(p>0.05)$ from untreated and other modified starches. Oxidized starch had the lowest amylose content (10.01\%) and was significantly different $(p>0.05)$ from other starches. Amylose contents of the native and modified starches were low when compared to other roots and tubers such as white yam Dioscorea rotundata species (27.48-31.55\%), taro (27.65-35.90\%), sweet potato $(28.69 \%$ ) (Addy et al., 2014; Himeda et al., 2012; Aprianita et al., 2009). Low contents of amylose observed in the starches could enhance swelling of the starches when incorporated into food products (Tester and Morrison, 1990) with a low tendency to retrograde. Moisture content of alkali-modified starch was higher and significantly different $(p>$ $0.05)$ from other starches. Moisture contents of acid, alkali and oxidized starches were higher than the recommended value for flour. Therefore, they could easily be attacked by microorganisms. Low moisture contents are required in order to extend the shelf life during storage. Untreated, acetylated and pre-gelatinized starches could keep longer than other modified starches due to their low moisture contents. However, acid, alkali and oxidized starches could be further dried to extend their keeping quality.

Table II: Effect of modification on the granule size, amylose and moisture values of trifoliate yam starches

\begin{tabular}{llll}
\hline Treatment & Granule size $(\mu \mathrm{m})$ & Amylose $(\%)$ & Moisture Contents $(\%)$ \\
\hline RY & $3.50 \pm 1.23 \mathrm{~b}$ & $15.57 \pm 0.49 \mathrm{~b}$ & $13.50 \pm 0.45 \mathrm{~d}$ \\
AEY & $2.53 \pm 2.07 \mathrm{e}$ & $16.17 \pm 0.63 \mathrm{a}$ & $10.18 \pm 0.37 \mathrm{f}$ \\
ADY & $2.65 \pm 1.89 \mathrm{~d}$ & $11.36 \pm 0.72 \mathrm{~d}$ & $17.04 \pm 0.43 \mathrm{~b}$ \\
AKY & $2.66 \pm 0.97 \mathrm{~d}$ & $10.20 \pm 0.88 \mathrm{e}$ & $17.85 \pm 0.21 \mathrm{a}$ \\
OY & $2.91 \pm 0.81 \mathrm{c}$ & $10.01 \pm 0.39 \mathrm{e}$ & $16.09 \pm 0.40 \mathrm{c}$ \\
PY & $3.86 \pm 1.55 \mathrm{a}$ & $14.05 \pm 0.64 \mathrm{c}$ & $10.50 \pm 0.39 \mathrm{e}$ \\
\hline
\end{tabular}

Values with the same superscript down the column were not significantly different $(\mathrm{p}<0.05)$

RY- Raw yam starch, AKY-Alkali-treated starch, ADY-Acid-treated starch, OXY-Oxidized starch, PY-

Pre-gelatinized starch, AEY-Acetylated starch 
Effect of Modification on the Swelling Power of Trifoliate Yam Starches

Data for the swelling power of the starches are shown in figure II. Pre-gelatinized starch increased from 2.15 at $60{ }^{\circ} \mathrm{C}$ to 3.00 at $70{ }^{\circ} \mathrm{C}$. The values of pre-gelatinized starches decreased at 80 to $90{ }^{\circ} \mathrm{C}$. This indicated that the pre-gelatinized starch swelled at low temperature from 60 to $70{ }^{\circ} \mathrm{C}$ and reduction in the values occurred at higher temperatures from $80^{\circ} \mathrm{C}$ and above. This may be due to the treatment (cooking) given to the starch as this caused reduction in the swelling ability of the starch at high temperatures. Native, acetylated and oxidized starches had similar trend in swelling power. The starches increased with increase in temperature with acetylated having a higher value (2.47) than the native (2.33) and oxidized (2.01) starches at $90{ }^{\circ} \mathrm{C}$. According to Bello-Pérez et al., (2006) increase in swelling power is related to the breaking of intermolecular hydrogen bonds in amorphous areas allowing progressive water absorption. There was a reduction in the swelling power of acid and alkali modified starches at high temperatures. The values were higher at $60{ }^{\circ} \mathrm{C}$ but decline till $90^{\circ} \mathrm{C}$ in both starches. This showed that acid and alkali- modified starches had low tendency to swell. The starch components dissolved in the medium and form a clear liquid solution. The higher the temperature, the more the starch dissolves in the medium thereby reducing the starch sediments. Acid and alkali treatment cause hydrolysis of the starch components thereby making the starch miscible with the medium. The swelling power of acidthinned starches decreased with the increase temperature. Thys et al. (2013) and Sandhu et al., (2007) explained that during acid hydrolysis the amylose chains are fragmented forming a disorganized structure that cannot retain water during temperature increases. Vaclavik and Christian (2008) also observed that hydrolysis of the starch molecule results in less water absorption by the starch granule, thus causing thinner hot paste and less firm cooled product.

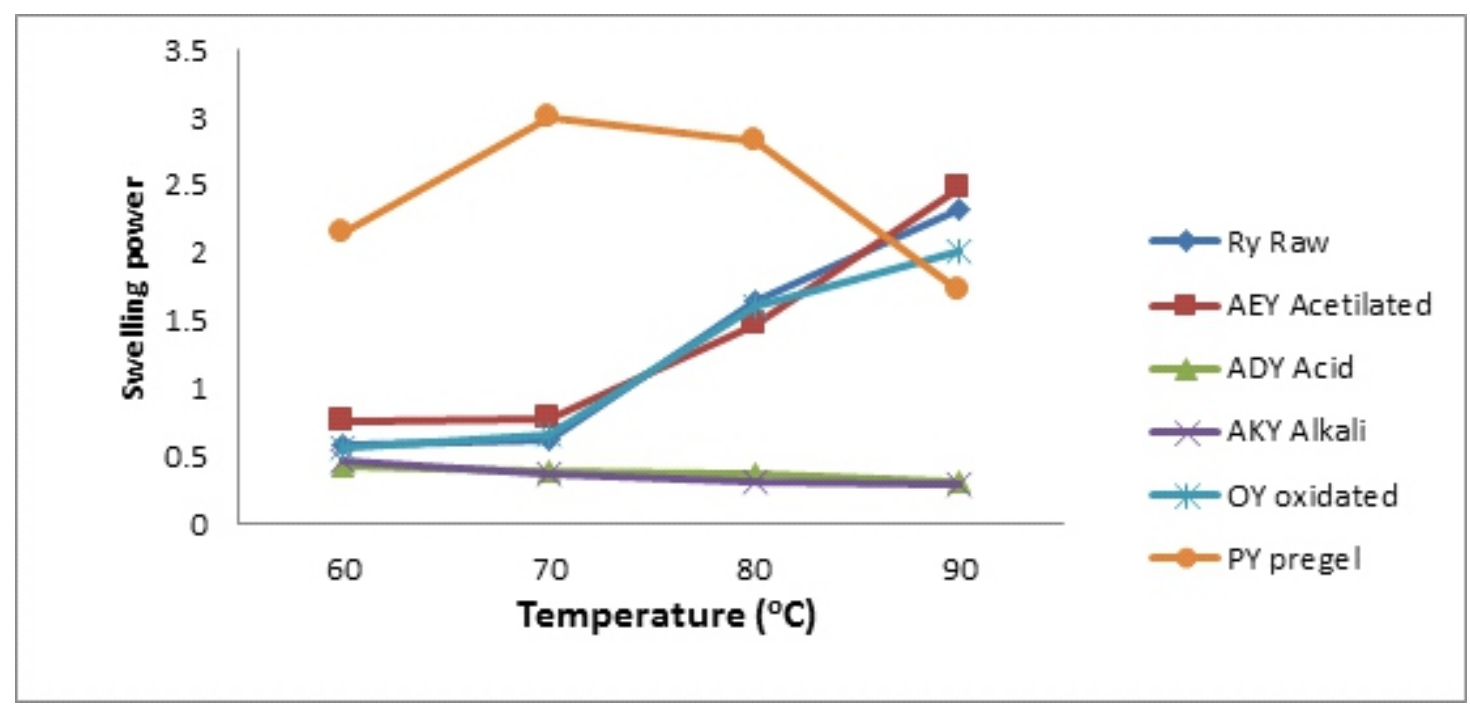

Figure II: Effect of modification on the swelling power of trifoliate yam starches RY- Raw yam starch, AKY-Alkali-treated starch, ADY-Acid-treated starch, OXY-Oxidized starch, PYPre-gelatinized starch, AEY-Acetylated starch 


\section{Effect of Modification on Paste Clarity of Trifoliate Yam Starches}

The initial paste clarity was high in acid and alkalimodified starches with values of $22.9 \%$ and $20.9 \%$ respectively (Figure III). At $4{ }^{\circ} \mathrm{C}$, the transmittance of acid-modified starch reduced $(6.4 \%)$ drastically at $24 \mathrm{~h}$ interval but at $48 \mathrm{~h}$ interval, the transmittance increased slightly and later declined to $6.1 \%$. For alkaline treated starch, transmittance also reduced to $2.7 \%$ at $24 \mathrm{~h}$ and there was a decrease in the values till $72 \mathrm{~h}$. Other starches such as the untreated, acetylated, oxidized and pre-gelatinized starches decreased in clarity with storage days. For the samples stored at ambient temperature, a sharp increase was noticed with oxidized starch from $2.0 \%$ to $17.6 \%$ at $24 \mathrm{~h}$ and later declined till $72 \mathrm{~h}$. For the acid and alkalimodified starches, rapid reduction in transmittance was noticed at $24 \mathrm{~h}$ but there was an

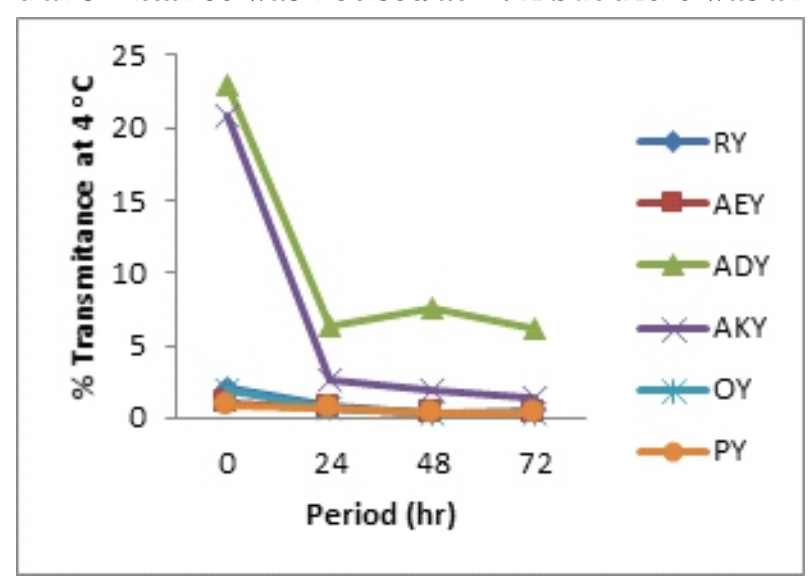

increase in the values at 48 and $72 \mathrm{~h}$. The same trend was observed in the untreated starch and pre-gelatinized starches as there was a reduction in transmittance at $24 \mathrm{~h}$ while the values increased at $48 \mathrm{~h}$ but later declined at $72 \mathrm{~h}$. Native and modified trifoliate yam starches were clearer after preparation of the solution but became opaque and cloudy with storage both at ambient and refrigerated temperatures. Acid-treated starch exhibited higher paste clarity at refrigerated temperature than ambient temperature but at ambient temperature, oxidized starch had higher paste clarity during storage at 24 and $48 \mathrm{~h}$. Starch paste clarity decreased during storage and this was in agreement with the report of Haghayegh and Schoenlechner (2010). According to Craig et al., (1989), low transmittance indicated high opacity in the starch solution.

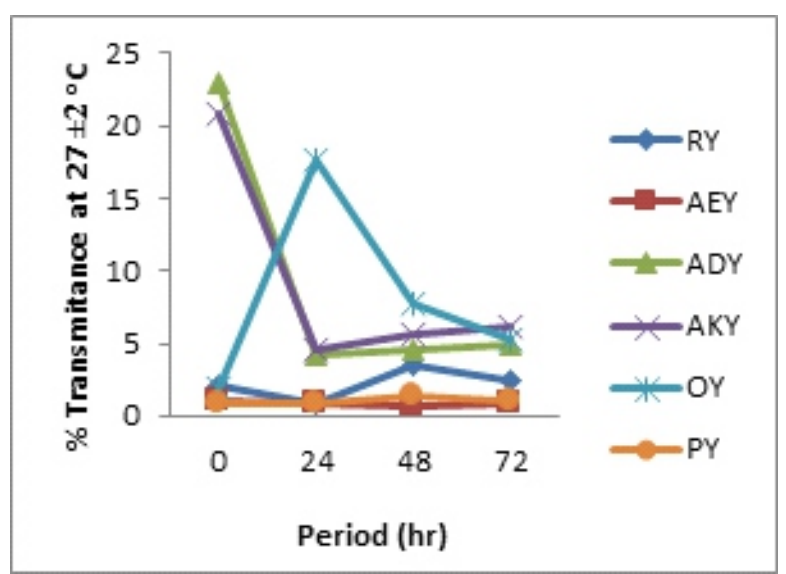

Figure III: Effect of modification on the percentage transmittance of trifoliate yam starches RY- Raw yam starch, AKY-Alkali-treated starch, ADY-Acid-treated starch, OXY-Oxidized starch, PYPre-gelatinized starch, AEY-Acetylated starch

Effect of Modification on Freeze-Thaw Stability of Trifoliate Yam Starches

Native and modified starches had higher water exudate at day 0 (Figure IV). The values decreased in all the starches at day 3 and there was a progressive increase in the amount of water exudate at day 10. Acetylated starch had higher freeze-thaw stability due to the least amount of water exudate observed in the starches during storage. The oxidized starch also had low freezethaw stability than the pre-gelatinized, acid and alkali starches. Acid and alkali-treated starches had low freeze-thaw stability throughout the storage periods. The amount of water exudate was due to the re-association of starch molecules, resulting in the formation of insoluble aggregates.
However, Ferrero et al., (1994) and Lutfi and Hasnain (2013) classified the gels as weepy, grainy, or spongy in nature. Furthermore, Ferrero et al., (1994) explained further that during freezing, starch regions were created in the matrix and the water present in the matrix remained partially unfrozen. The concentration of starch in the matrix affects the association of starch chains in forming thick filament. However, the water molecules coagulate into ice crystals forming a separate phase in which the ice is converted to bulk phase water during thawing resulting in release of water from the polymeric network (syneresis). The water thus released leaves the starch gel with a sponge-like texture. 


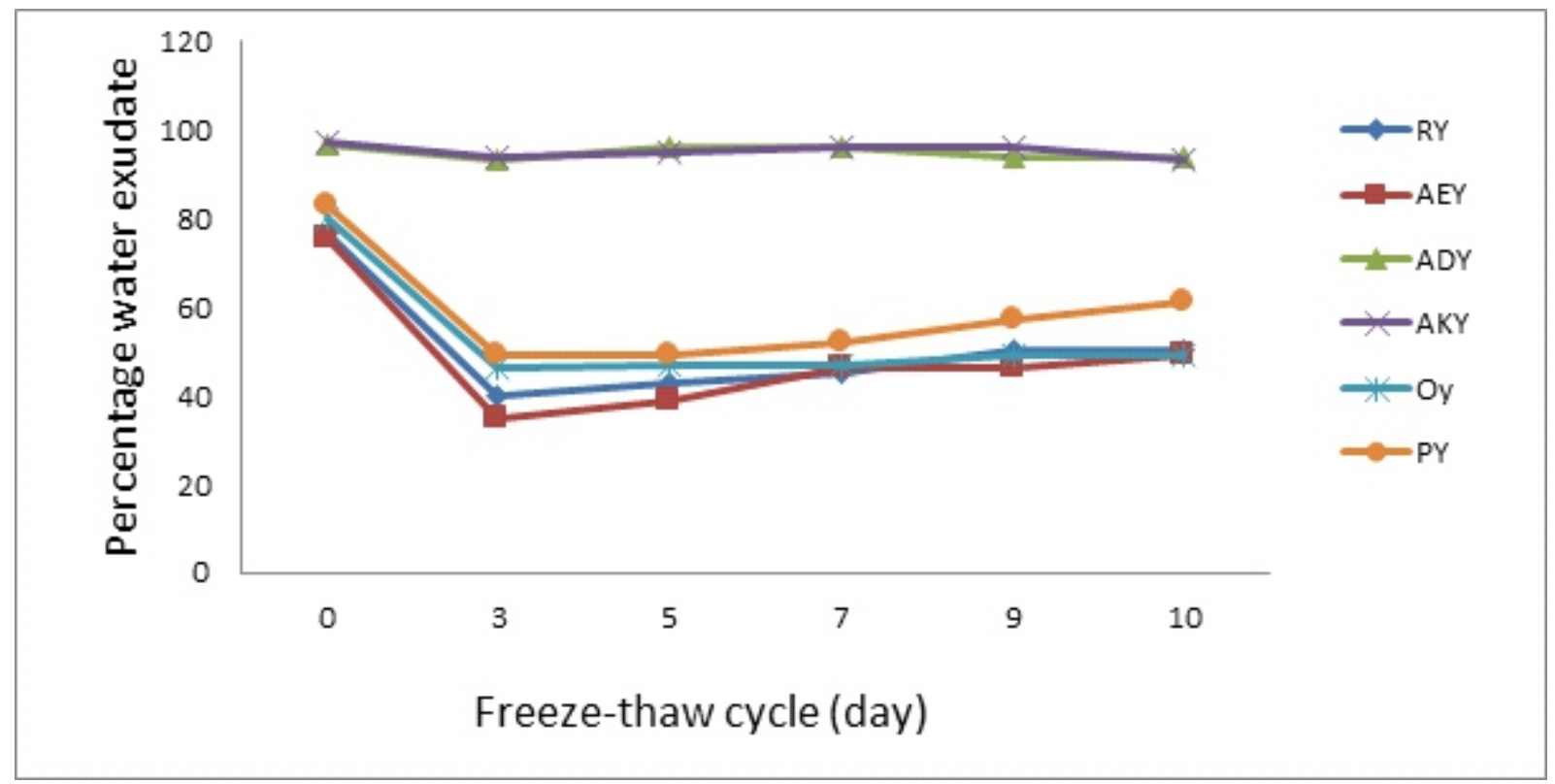

Figure IV: Effect of modification on freeze-thaw stability of trifoliate starches at $5 \%(\mathrm{w} / \mathrm{v})$ Concentration

RY- Raw yam starch, AKY-Alkali-treated starch, ADY-Acid-treated starch, OXY-Oxidized starch, PYPre-gelatinized starch, AEY-Acetylated starch

\section{Effect of Modification on Pasting Properties of Trifoliate Yam Starches}

Acetylated starch had higher peak viscosity $(3833.00 \mathrm{cP})$ but was not significantly different $(\mathrm{p}>0.05)$ from untreated, oxidized and pregelatinized starches (Table III). No significant differences $(\mathrm{p}>0.05)$ were observed in the peak viscosity values of acid and alkali-treated starches. Pre-gelatinized starch had higher holding strength which was not significantly different $(p>0.05)$ from the untreated starch sample. Untreated, acetylated and oxidized starches were not significantly different $(p>0.05)$ from each other. Likewise, no significant differences $(p>0.05)$ existed between the acid and alkali-treated starches in holding strength. Higher breakdown viscosity (2083.50 cP) was observed in acetylated starch followed by the untreated and oxidized starches respectively. No significant differences ( $p$ $<0.05)$ were observed in oxidized and pregelatinized starches, acid and alkali-treated starches in breakdown viscosities. Lower breakdown viscosities were observed in acid and alkali-treated starches with a value of 7.50 and $8.50 \mathrm{cP}$ respectively. PY had higher final viscosity
(5813.50 cP) and setback (3090.00 cP) respectively. These values were significantly different $(p<0.05)$ from the untreated and other modified starches. There were no significant differences $(p>0.05)$ in the final viscosities and setback values obtained for untreated, acetylated and oxidized starches. However, the final viscosities, setback and pasting time values obtained for acid and alkali-treated starches were not significantly different $(p<0.05)$ from each other. PY had a higher cooking time (7.00 min) but at lower temperature $\left(71.78{ }^{\circ} \mathrm{C}\right)$ than other starches. Pasting temperatures of untreated, acetylated and oxidized starches were not significantly different $(\mathrm{p}<0.05)$ while the temperatures for acid and alkali-treated starches were not detected. Pasting temperature showed the minimum temperature for starch gelatinization. Moreover, Altay and Gunasekaran (2006) reported that starch gelatinization depends on water content, heating rate, the botanical source of starch, processes applied to starch before gelatinization, and amylose/amylopectin content of starch. 
Table III: Effect of Modification on the Pasting Properties of Trifoliate Starches

\begin{tabular}{llllllll}
\hline Treatment & Peak $(\mathrm{cP})$ & $\begin{array}{l}\text { Holding strength } \\
(\mathrm{cP})\end{array}$ & $\begin{array}{l}\text { Breakdown } \\
(\mathrm{cP})\end{array}$ & $\begin{array}{l}\text { Final viscosity } \\
(\mathrm{cP})\end{array}$ & $\begin{array}{l}\text { Setback } \\
(\mathrm{cP})\end{array}$ & $\begin{array}{l}\text { Pasting time } \\
(\mathrm{min})\end{array}$ & $\begin{array}{l}\text { Pasting } \\
\text { temperature } \\
\left({ }^{\circ} \mathrm{C}\right)\end{array}$ \\
\hline RY & $3579.00 \pm 1.30 \mathrm{a}$ & $2112.00 \pm 9.33 \mathrm{ab}$ & $1467.00 \pm 3.68 \mathrm{~b}$ & $2797.00 \pm 7.50 \mathrm{~b}$ & $685.00 \pm 1.84 \mathrm{~b}$ & $5.10 \pm 0.04 \mathrm{~b}$ & $84.43 \pm 0.64 \mathrm{a}$ \\
$\mathrm{AEY}$ & $3833.00 \pm 1.32 \mathrm{a}$ & $1749.50 \pm 8.70 \mathrm{~b}$ & $2083.5 \pm 5.96 \mathrm{a}$ & $2591.00 \pm 4.53 \mathrm{~b}$ & $841.50 \pm 4.17 \mathrm{~b}$ & $4.90 \pm 0.04 \mathrm{c}$ & $83.28 \pm 0.04 \mathrm{a}$ \\
$\mathrm{ADY}$ & $-29.00 \pm 2.83 \mathrm{~b}$ & $-36.50 \pm 0.71 \mathrm{c}$ & $7.50 \pm 2.12 \mathrm{~d}$ & $-33.50 \pm 0.71 \mathrm{c}$ & $3.00 \pm 1.41 \mathrm{c}$ & $1.10 \pm 0.04 \mathrm{e}$ & $\mathrm{ND}$ \\
$\mathrm{AKY}$ & $-30.00 \pm 1.41 \mathrm{~b}$ & $-38.50 \pm 0.71 \mathrm{c}$ & $8.50 \pm 0.71 \mathrm{~d}$ & $-36.00 \pm 0.00 \mathrm{c}$ & $2.51 \pm 0.71 \mathrm{c}$ & $1.07 \pm 0.00 \mathrm{e}$ & $\mathrm{ND}$ \\
OY & $2964.50 \pm 1.95 \mathrm{a}$ & $1915.5 \pm 1.04 \mathrm{~b}$ & $1049.00 \pm 9.50 \mathrm{c}$ & $2581.50 \pm 1.10 \mathrm{~b}$ & $666.00 \pm 5.66 \mathrm{~b}$ & $4.67 \pm 0.09 \mathrm{~d}$ & $84.00 \pm 0.07 \mathrm{a}$ \\
PY & $3628.50 \pm 5.34 \mathrm{a}$ & $2723.00 \pm 3.68 \mathrm{a}$ & $905.50 \pm 6.17 \mathrm{c}$ & $5813.50 \pm 2.19 \mathrm{a}$ & $3090.00 \pm 5.86 \mathrm{a}$ & $7.00 \pm 0.00 \mathrm{a}$ & $71.78 \pm 3.36 \mathrm{~b}$ \\
\hline
\end{tabular}

Values with the same superscript down the column were not significantly different $(\mathrm{p}<0.05)$

RY- Raw yam starch, AKY-Alkali-treated starch, ADY-Acid-treated starch, OXY-Oxidized starch, PYPre-gelatinized starch, AEY-Acetylated starch, ND- Not detected

\section{CONCLUSIONS}

The work determined the effect of modification on the properties of trifoliate yam starch. The colour of alkali-treated starch was lighter than other starches. Pre-gelatinized starch was reddish/yellowish in colour and was significantly different $(p<0.05)$ from other starches. Smaller granule sizes were observed for the starches. Acetylated starch had higher amylose content while the least value was observed in the oxidized starch. Pre-gelatinized, alkali and acid-treated starches swelled at lower temperature and decreased in swelling power at higher temperatures. However, oxidized, acetylated and native starches increased in swelling power with increased temperature. Decrease in paste clarity was observed for all the starches at $4{ }^{\circ} \mathrm{C}$ and at ambient temperature during storage. The amounts of water exudates in acid and alkalitreated starches were higher than other starches indicating low freeze-thaw stability. Peak viscosity was higher in acetylated starch while the native starch had higher final viscosity with higher setback value. Therefore, the starches could be used in different applications in food industry as thickeners, gel, stabilizer and in the food formulation.

\section{ACKNOWLEDGEMENT}

The research work was supported by Osun State Polytechnic Research Grant (TETFUND/DESS/POLY/IREE/RP/VOL.II ) Iree, Nigeria.

\section{REFERENCES}

Abbas, K.A., Khalil, S.K. and Hussin, A.S.M. (2010). Modified starches and their usages in selected food products: A Review Study. Journal of Agricultural Science 2(2): 90 100

Addy, R.N. A, Wireko-Manu, F.D. and Oduro, I. (2014). Physicochemical and pasting properties of starch extracted from four yam varieties. Journal of Food and Nutrition Sciences 2 (6), 262-269.

Adetunji, O.A., Odeniyi, M.A. and Itiola, O.A. (2006). Compression, mechanical and release properties of chloroquine phosphate tablets containing corn and trifoliate yam starches as binders. Tropical Journal of Pharmaceutical Research 5(2): 589596

Akinoso, R. and Abiodun, O.A. (2013). Effect of harvesting periods on the morphology and physico-chemical properties of trifoliate yam starches. Starch/Starke 65: 753-761.

Akinwande, B. A., Adeyemi, I. A., Maziya-Dixon, B. and Asiedu, R. (2007). Effect of tuber harvesting time and storage period on the pasting properties of yam (Dioscorea rotundata) starch. World Journal of Agricultural Sciences 3(6): 781-787.

Altay, F. and Gunasekaran, F.S. (2006). Influence of drying temperature, water content, and heating rate on gelatinization of corn starches. Journal of Agriculture and Food Chemistry 54(12): 4235-4245.

AOAC (2006). Official method of analysis (18 ${ }^{\text {th }}$ ed.) Washington, D.C: Association of Official Analytical Chemist.

Aprianita, A., Purwandari, U., Watson, B. and Vasiljevic, T. (2009). Physico-chemical properties of flours starches from 
selected commercial tubers available in Australia. International Food Research. Journal 16: 507-520

Bello-Perez, L. A., Garcia-Suarez, F. J., MendezMontealvo, G., Nascimento, J. R. O., Lajolo, F. M. and Cornenunsi, B. R. (2006). Isolation and characterization of starch from seeds of Araucaria brasiliensis: A novel starch for application in food industry. Starch/Stärke 58: 283-291.

Chung, H.J., Shin, D.H. and Lim, S.T. (2008). In vitro starch digestibility and estimated glycemic index of chemically- modified corn starches. Food Research International, 41: 579-585

Craig, S. A., Maningat, C. G., Seib, P. A. and Hoseney, R. C. (1989). Starch paste clarity. CerealChemistry, 66:173-182.

Eliasson, A.C. and Gudmundsson, M. (1996). Starch: Physicochemical and functional aspects. In A.C. Eliasson (Ed.), Carbohydrates in food pp. 431-503. New York: Marcel Dekker.

Ferrero, C., Martino, M.N. and Zaritzky, N.E. (1994). Corn starch - xanthan gum interaction and its effect on the stability during storage of frozen gelatinized suspensions. Starch/Stärke, 46: 300-308.

Gutiérrez, T.J., Pérez, E., Guzmán, R., Tapia, M.S. and Fama, L. (2014). Physicochemical and functional properties of native and modified by crosslinking, dark-cush-cush yam (Dioscorea Trifida) and cassava (Manibot Esculenta) starch. Journal of Polymer and Biopolymer Physics Chemistry 2(1): 1-5

Haghayegh, G. and Schoenlechner, R. (2010). Comparison of functional properties of isolated emmer and einkorn wheat starches. Journal of Food, Agriculture \& Environment, 8 (3 \& 4): 239-243

Himeda, M., Yanou, N.N., Nguimbou, R.M., Gaiani, C., Scher, J., Facho, J.B. and Mbofung, C.M.F. ( $(201212)$. Physicochemical, rheological and thermal properties of taro (Colocassia esculenta) starch harvested at different maturity stages. International Journal of Biosciences, 2 (3): 14-27

Iheagwara, M. C. (2012). Physicochemical and retrogradation characteristics of modified sweet potato (Ipomoea batatas L. (Lam)) starch. Journal of Agriculture and Food Technology 2(3): 49-55.

Juliano, B. O. (1971). A simplified assay for milled rice amylose. Cereal Science Today 16: 334340.

Jyothi, A.N., Sajeev, M.S. and Padmaja, G. (2013). Promising tubers for industrial revolution. Indian Horticulture 58(3): 28-33

Lutfi, Z. and Hasnain, A. (2013). Freeze-thaw stabilization of water chestnut (Trapa bispinosa) starch in the presence of gums and salts. Trakia Journal of Sciences, 2: 163169

Okunlola, A. and Akingbala, O. (2013).Characterization and evaluation of acid-modified starch of Dioscorea oppositifolia (Chinese yam) as a binder in chloroquine phosphate tablets. Brazilian Journal of Pharmaceutical Sciences 49(4): 701708.

Peroni, F.H.G., Rocha, T.S. and Franco, C.M.L. (2006). Some structural and physicochemical characteristics of tuber and root starches. Food Science and Technology International, 12: 505-513.

Odeniyi M.A., Ayorinde, J.O. (2012). Material and rheological properties of yam starch/polymer blend hydrogels. International Journal of Pharmacology and Pharmaceutical Technology, 1(2):23-28

Oladebeye, A. O., Oshodi, A. A., Oladebeye, A.A. and Amoo, I. A. (2011). Pasting properties of heat-moisture treated starches of white and yellow yam (Dioscorea specie) cultivars. Nature and Science, 9(1):29-33

Otegbayo, B., Oguniyan, D., Akinwumi, O. (2013). Physicochemical and functional characterization of yam starch for potential industrial applications. Starch/Stärke 65: 1-16. DOI 10.1002/star.201300056

Sandhu, K. S., Singh, N., Lim, S. T. (2007). A comparison of native and acid thinned normal and waxy corn starches: Physicochemical, thermal, morphological and pasting properties. LebensmittelWissenschaft \& Technologie, 40: 1527-1536

Santana, A.L., Angela, M. and Meireles, A. (2014). New starches are the trend for industry applications: A review. Food and Public Health. 4(5): 229-241 
Sathe, S.K.and Salunkhe, D.K. (1981). Isolation partial characteriszation and modification of great Northern Bean (Phaseolus vulgaris L.) starch. Journal of Food Science, 46, 617621.

Sukhija, S., Singh, S. and Riar, C.S. (2016). Effect of oxidation, cross-linking and dual modification on physicochemical, crystallinity, morphological, pasting and thermal characteristics of elephant foot yam (Amorphophallus paeoniifolius) starch. Food Hydrocolloids, 55: 56-64

Tako, M., Tamaki, Y., Teruya, T. and Takeda, Y. (2014). The principles of starch gelatinization and retrogradation. Food and Nutrition Sciences 5: 280-291

Tester, R.F. and Morrison, W.R. (1990). Swelling and gelatinization of cereal starches. I. Effect of amylopectin, amylose and lipids. CerealChemistry 67:551-559

Thys, R.C.S., Aires, A.G., Marczak, L.D.F.,
Noreña, C.P.Z. (2013). The effect of acid hydrolysis on the technological functional properties of pinhão (Araucaria brasiliensis) starch. Ciência e Tecnologia de Alimentos 33: http://dx.doi.org/10.1590/S0101 20612013000500014

Vaclavik, V.A. and Christian E.W. (2008). Starches in food. Essentials of Food Science. $3^{\text {rd }}$ Edition. Springer publisher. Pp 49-65

Wang, S.1. and Copeland, L. (2015). Effect of acid hydrolysis on starch structure and functionality: a review. Critical Reviews in Food Science and Nutrition 55(8): 10811097.

Zięba, T., Kapelko, M., Gryszkin,A. and Brzozowska, M. (2010). Physical and chemical modification of potato starch to obtain resistant starch preparations. Polish Journal of Food and Nutrition Sciences 60(2): 153-157 